\title{
Review
}

Bringing Mentally Handicapped Children Out of Hospital. Ann Shearer. King's Fund Project Paper Number 30. King's Fund Centre, 126 Albert Street, London, NW1 7NF. November 1981. £1.00.

This Project Paper is a report of a Conference sponsored by the DHSS and held in June 1981 at the King's Fund Centre. The aim of the Conference was to promote the speedy removal of the 3,000 mentally handicapped children who still live in our subnormality hospitals. It brought together information on various schemes in different parts of the country, which are being tried by health authorities and social services departments as well as voluntary bodies.

The excellent introduction to the booklet describes the complex background to the current DHSS policy that severely mentally handicapped children should be cared for in small 'homely' units, not in hospital. This view is based partly on the research findings that children living outside institutions have superior functioning as well as a better quality of life, e.g. Tizard's Brookland's Experiment; partly on the stark realities of present-day life in hospital (see Maureen Oswin's report 'Children in Long Stay Hospitals'); and partly on the recognition that 'mentally handicapped children have more in common with other children because of their childhood, than with mentally handicapped adults because of their common disability' (Court Committee, 1976), and therefore should be cared for separately from adults. However, the actual process of moving children has been very slow - most of the decrease in numbers of children in hospital being due to them reaching their 16th birthday, rather than being discharged. So far, only the Wessex Region has a comprehensive plan to replace all its children's wards with small local units, and these 'Wessex Units' are still regarded by many as experimental.

The Conference drew together the various alternatives to hospital that are being tried: adoption, fostering, ordinary children's homes, specialist homes and specialist treatment units. An example of each of these alternatives is described in the Paper, illustrated by case material.

The Paper then considers the administrative issues involved in the change from hospital to community careparticularly financing. Several possible manoeuvres are described with examples from schemes to illustrate each one: e.g., transferring money within authorities using joint finance. It also outlines many other imaginative ideas for overcoming these difficulties contained in the DHSS Consultative Document, Care in the Community (July 1981).

The next section entitled 'Making a Start' provides practical guidelines for health and local authorities setting out on the task of moving children out of hospital. This section refers to the National Development Group's report 'Helping Mentally Handicapped People in Hospital' which stresses the need for multidisciplinary assessments of each child, and for close cooperation between health and local authorities and voluntary organizations in planning a pattern of care to meet each child's individual needs.

A short appendix on the practical aspects of fund raising by the National Appeals Director of MENCAP complete the Paper.

Ann Shearer's style is clear and concise, and remarkably effective in reaching the kernel of the many DHSS reports she cites. Although the sections are brief, containing only an outline of the subject, references and sources of further information are provided at the end of each section. The difficulties as well as the successes of the schemes are described, and the problems to be encountered in 'habilitating' long-stay children are acknowledged. However, for anyone attempting to move children out of hospital, the Paper provides encouraging reading and contains much practical information-particularly in the area of overcoming administrative 'blocks'. It should be read by administrators, doctors, nurses, social workers, psychologists and anyone involved in the care of mentally handicapped children. In providing us with examples of schemes which have overcome the practical problems of resource constraints, the Paper confronts us with the real issue that may hinder progress - the motivation of health and local authorities and voluntary bodies to put aside their differences and imaginatively work together to achieve a better quality of life for severely mentally handicapped children in hospital.

GILLIAN C. FORREST

\section{The Park Hospital}

Oxford

\section{REFERENCES}

Department of Health and Social Securrty (1971) Better Services for the Mentally Handicapped. Cmnd. 4683, HMSO.

(1978) Helping Mentally Handicapped People in Hospital. A Report to the Secretary of State for Social Services by the National Development Group for the Mentally Handicapped.

Oswin, M. (1978) Children Living in Long Stay Hospitals. Spastics International Medical Publications/Heinemann Medical Books.

TIZARD, J. (1960) Residential care of mentally handicapped children. British Medical Journal, pp. 1041-46.

COURT REPORT (1976) Fit for the Future: Report of the Committee on Child Health Services. Cmnd. 6684, HMSO. 